\title{
CACNA1A haploinsufficiency causes cognitive impairment, autism and epileptic encephalopathy with mild cerebellar symptoms
}

\author{
Lena Damaj ${ }^{1,2}$, Alexis Lupien-Meilleur ${ }^{3}$, Anne Lortie ${ }^{1,3}$, Émilie Riou ${ }^{4}$, Luis H Ospina ${ }^{5}$, Louise Gagnon ${ }^{1}$, \\ Catherine Vanasse $^{1}$ and Elsa Rossignol ${ }^{\star, 1,3}$
}

CACNA1A loss-of-function mutations classically present as episodic ataxia type 2 (EA2), with brief episodes of ataxia and nystagmus, or with progressive spinocerebellar ataxia (SCA6). A minority of patients carrying CACNA1A mutations develops epilepsy. Non-motor symptoms associated with these mutations are often overlooked. In this study, we report 16 affected individuals from four unrelated families presenting with a spectrum of cognitive impairment including intellectual deficiency, executive dysfunction, ADHD and/or autism, as well as childhood-onset epileptic encephalopathy with refractory absence epilepsy, febrile seizures, downbeat nystagmus and episodic ataxia. Sequencing revealed one CACNA1A gene deletion, two deleterious CACNA1A point mutations including one known stop-gain and one new frameshift variant and a new splice-site variant. This report illustrates the phenotypic heterogeneity of CACNA1A loss-of-function mutations and stresses the cognitive and epileptic manifestations caused by the loss of Cav2.1 channels function, presumably affecting cerebellar, cortical and limbic networks. European Journal of Human Genetics (2015) 23, 1505-1512; doi:10.1038/ejhg.2015.21; published online 4 March 2015

\section{INTRODUCTION}

The CACNA1A gene on chromosome 19p13 encodes the alpha1 subunit of the $\mathrm{Ca}_{\mathrm{V}} 2.1 \mathrm{P} / \mathrm{Q}$-type voltage-gated calcium channel. Mutations in this gene cause three allelic autosomal dominant conditions: episodic ataxia type 2 (EA2, OMIM: 108500), spinocerebellar ataxia type 6 (SCA6, OMIM: 183086) and familial hemiplegic migraine type 1 (FHM1, OMIM:141500). ${ }^{1-3}$ These conditions occasionally overlap since patients with FHM1 may have cerebellar symptoms, and 33\% of patients with SCA6 display episodic features characteristic of EA2. ${ }^{4-6}$ EA2 usually presents during childhood or early adulthood ${ }^{7}$ with intermittent episodes of ataxia and nystagmus lasting minutes to days. ${ }^{8}$ These episodes are classically triggered by exertion, stress, heat, fever, alcohol, caffeine or drugs such as phenytoin. ${ }^{9}$ They tend to respond to acetazolamide or 4-aminopyridine (4-AP). A downbeat nystagmus often persists between episodes. ${ }^{10}$ Most patients eventually develop progressive ataxia with cerebellar atrophy. ${ }^{7}$ A minority of patients present generalized absence epilepsy ${ }^{11}$ and/or learning difficulties, ${ }^{5}$ but the extent of neurocognitive impairment associated with these mutations has not been fully described to date.

We describe four French Canadian non-consanguineous families with 16 affected individuals carrying CACNA1A loss-of-function mutations and presenting with epileptic encephalopathy or cognitive impairment including intellectual disability (ID), ADHD or autism, as well as downbeat nystagmus and intermittent ataxia, which did not dominate the clinical picture.

\section{METHODS}

All patients were investigated on a clinical basis at the CHU Ste-Justine. Informed consent was obtained for genetic testing in accordance with the institution's ethics committee board requirements. Comparative genomic hybridization (CGH) assays were conducted at the CHUSJ using a 135kfeature whole-genome microarray (SignatureChip OS2.0 manufactured for Signature Genomic Laboratories (Spokane, WA, USA) by Roche NimbleGen, Madison, WI, USA; based on UCSC 2006 hg18 assembly), or at the CHUS using a 180k-feature whole-genome microarray (Cytosure ISCAv2, 4x180k, Oxford Gene Technology, Becgbroke, UK), according to the manufacturers' protocols. Genomic coordinates indicate the minimal size of the CNVs. CACNA1A sequencing of the entire coding region (47 exons) and flanking exon-intron splice-site junctions was performed at Athena Diagnostics or at Medical Neurogenetics Laboratories. Variants identified in the course of this project were submitted to the ClinVar database (http://www.ncbi.nlm.nih.gov/ clinvar/) (\#SCV000196749-SCV000196752).

\section{RESULTS}

Clinical descriptions and investigations

The clinical presentation and investigations of patients recruited in this study are summarized in Table 1. Family trees are illustrated in Figure 1. Mutations are depicted in Figure 2. Detailed description for each case is provided in the following sections.

\section{Family 1}

Patient 4.1 was born at term after an unremarkable pregnancy and had normal early psychomotor development before seizure onset. $\mathrm{He}$ developed refractory epilepsy with generalized tonic-clonic seizures and absences starting at 11 months of age. His electroencephalograms (EEGs) were characterized by intermittent generalized theta activity with spikes or with intermittent bi-posterior spike-wave activity. The seizures were successively treated with a combination of valproic acid, topiramate and levetiracetam. He also presented with monthly

${ }^{1}$ Department of Pediatrics, Neurology Service, CHU Ste-Justine, U. de Montréal, Montreal, Quebec, Canada; ${ }^{2}$ Department of Pediatrics, Teaching Hospital of Rennes, Rennes, France; ${ }^{3}$ Department of Neuroscience, CHU Ste-Justine, U. de Montréal, Montreal, Quebec, Canada; ${ }^{4}$ Department of Pediatrics, CHUS, U. de Sherbrooke, Sherbrooke, Quebec, Canada; ${ }^{5}$ Department of Ophtalmology, CHU Ste-Justine, U. de Montréal, Montreal, Quebec, Canada

*Correspondence: Dr E Rossignol, Departments of Pediatrics and Neurosciences, CHU Ste-Justine and Research Center, Lab 5994, Montreal, Quebec, Canada H3T 1 C5. E-mail: elsa.rossignol@umontreal.ca

Received 3 July 2014; revised 15 January 2015; accepted 20 January 2015; published online 4 March 2015 
Cognitive impairment due to CACNA1A mutations

$L$ Damaj et al

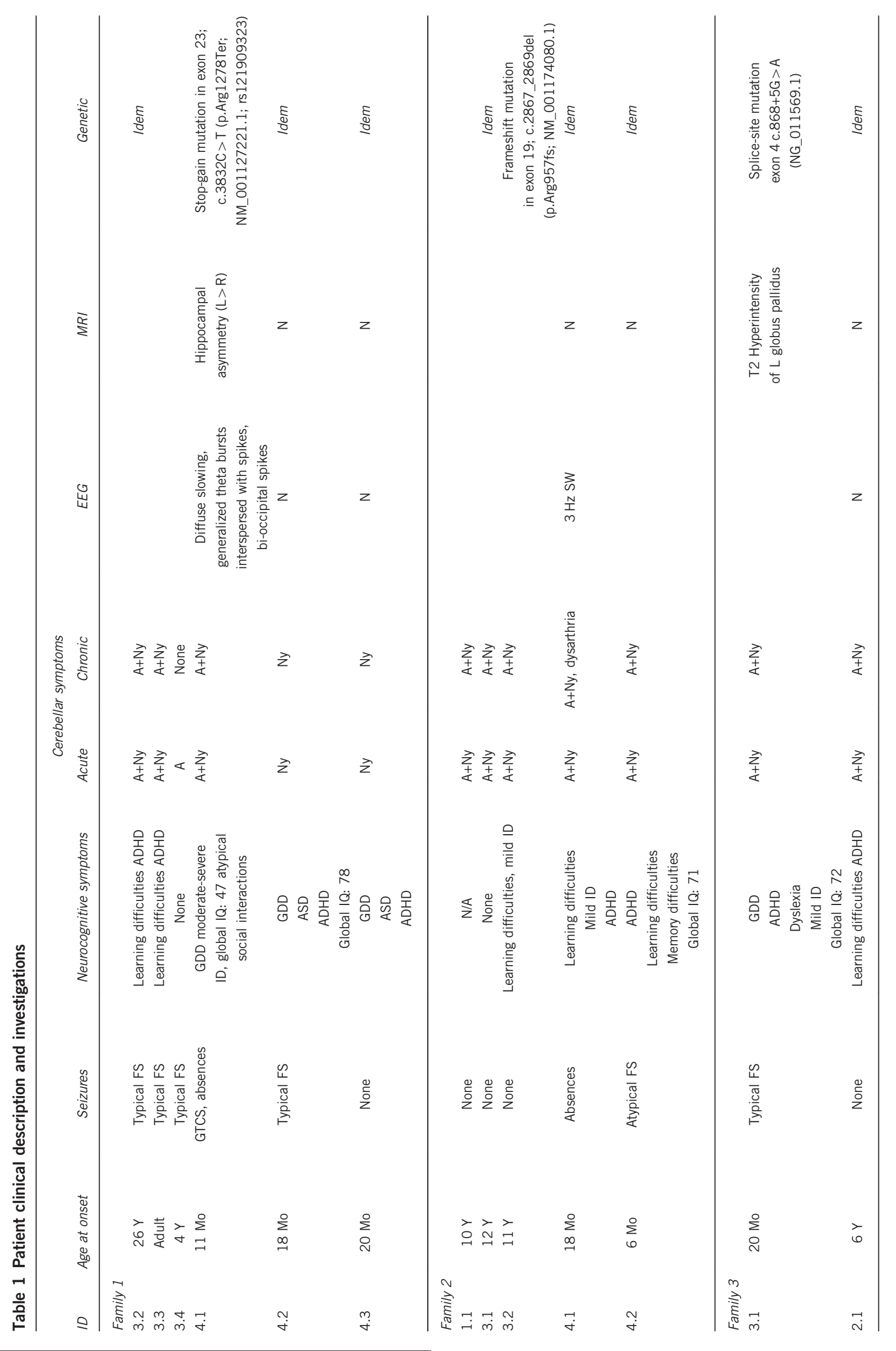

European Journal of Human Genetics 


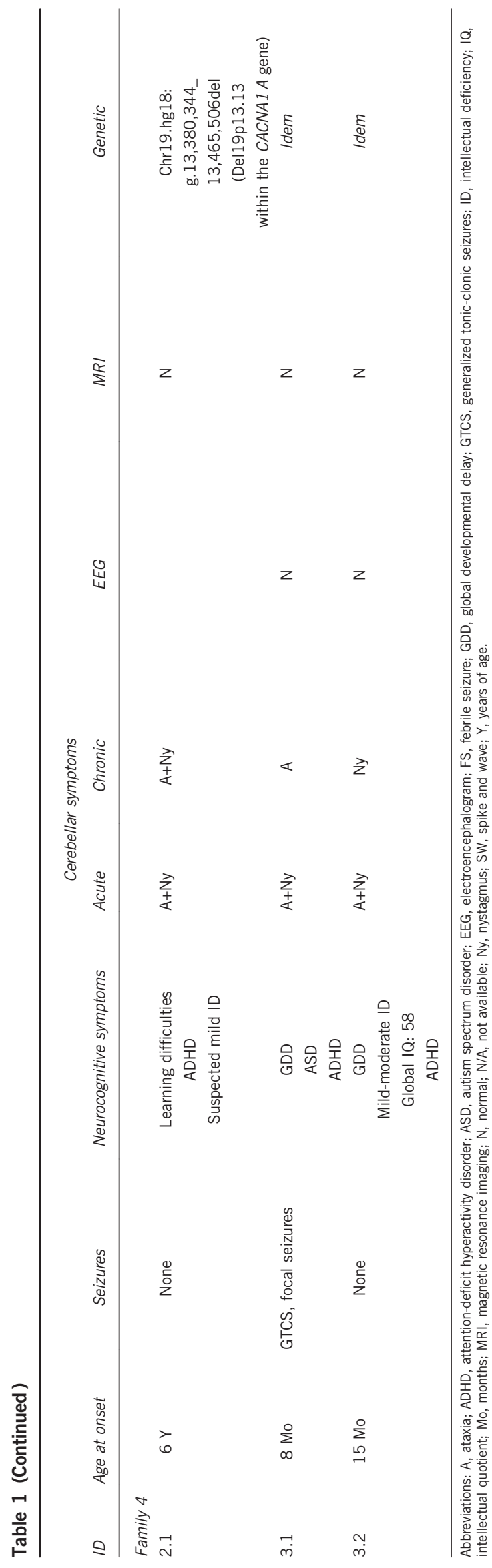

episodes of malaise, altered contact, hypotonia and nystagmus lasting 2-3 min, which did not respond to anticonvulsive drugs. The child's development was globally delayed, with significant language impairment at 18 months of age. At 6 years of age, he displayed a moderatesevere ID (global IQ: 47) with altered socialization skills. Upon examination, he presents a downbeat nystagmus and an unsteady broad-based gait, without frank dysmetria.

The child's father (3.2) presented with febrile seizures and learning disabilities with ADHD during childhood but completed his high school degree and is now employed. Upon questioning, he described intermittent episodes of ataxia, vertigo, vertical oscillopsia and dysarthria lasting 15-60 minutes, occurring every week, and triggered by stress, infections, fatigue and sweet foods, since the age of 26 years. These episodes had been attributed to hormonal imbalances although he had never consulted a neurologist for these symptoms. Interestingly, his twin brother (patient 3.3) presented similar episodic symptoms and suffered from impaired socialization skills, had learning disabilities, required special schooling and is currently unemployed. The twins' father (2.3) presents episodic ataxia and persistent nystagmus. Their brother (patient 3.4) presented febrile seizures during childhood. He displays infrequent (two to three times a year) episodes of ataxia lasting less than an hour and triggered by fatigue or exertion. This man has two children, a girl (patient 4.2) and a boy (patient 4.3), who both presented with global developmental delay (DD), autism and ADHD. Both children had single episodes of behavioral arrest with facial automatisms and had normal EEGs. On examination, both children display a downbeat nystagmus (see Supplementary Video S1) and gaze-evoked nystagmus without ataxia or dysmetria.

CGH and metabolic investigations were normal in all three children (including lactate, pyruvate, amino acid screen, organic acid screen, urinary purines and pyrimidines and urine creatine). Patient 4.3 underwent full ophtalmological workup, with normal electroretinogram. His brain magnetic resonance imaging (MRI) revealed slight size asymmetry of the hippocampi without structural anomalies, and normal cerebellar and brainstem structures. Brain MRIs of the two other children were normal. Targeted sequencing of the CACNA1A gene in all three children revealed a variant in exon 23 ; c.3832C $>\mathrm{T}$ (p.(Arg1278Ter; NM_001127221.1; NG_011569.1; rs121909323)) leading to a premature stop codon and previously associated with EA2. ${ }^{12,13}$ Additional sequencing of 35 known epileptic encephalopathy genes in patient 4.1 as described by Michaud et al, ${ }^{14}$ was performed and was negative.

\section{Family 2}

Patient 4.1 was born at term after an unremarkable pregnancy. $\mathrm{He}$ presented with global DD evolving toward mild ID, ADHD and learning difficulties. At 18 months of age, he developed refractory absences with daily episodes of brief behavioral arrests and facial automatisms. His EEGs reveal generalized spike-wave activity. His absences were refractory to valproic acid and ethosuximide but partially responsive to a combination of valproic acid and levetiracetam. In addition, this boy presents recurrent episodes of nystagmus without ataxia, lasting 5-15 s, occurring two to three times a day, often precipitated by fatigue or febrile illnesses. At 9 years of age, he remains with moderate global delay, delayed fine motor skills and he requires special education. His neurological examination reveals a familial macrocrania (98th percentile), downbeat nystagmus, hypometric saccades, slight dysarthria and unsteady gait without frank ataxia.

Upon questioning, the child's mother (patient 3.1) described episodes of ataxia, vertigo and nausea, without headache, lasting 
Family $1\left({ }^{*}\right.$ c. $\left.3832 \mathrm{C}>\mathrm{T}\right)$

1

3

4

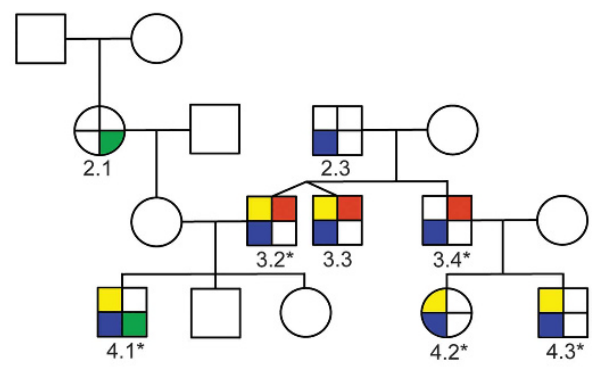

Family $3\left({ }^{*} \mathrm{c} .868+5 \mathrm{G}>\mathrm{A}\right)$

1
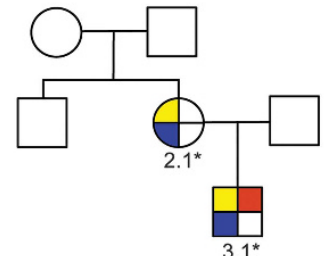

Family 2 ( ${ }^{*}$ c.2867_2869del)

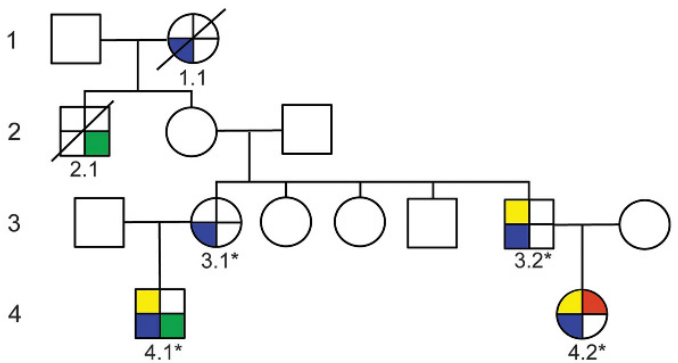

Family 4 (* Del 19p13.13)

1

2

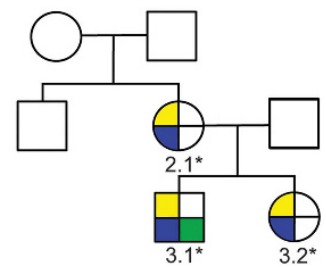

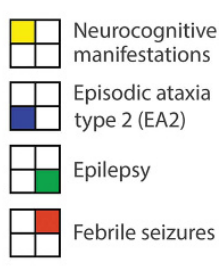

Figure 1 Family trees. The genealogical tree for each family is illustrated, with color-coding for associated symptoms (cf inset). Asterisks denote patients for which CACNA1A mutations were confirmed.

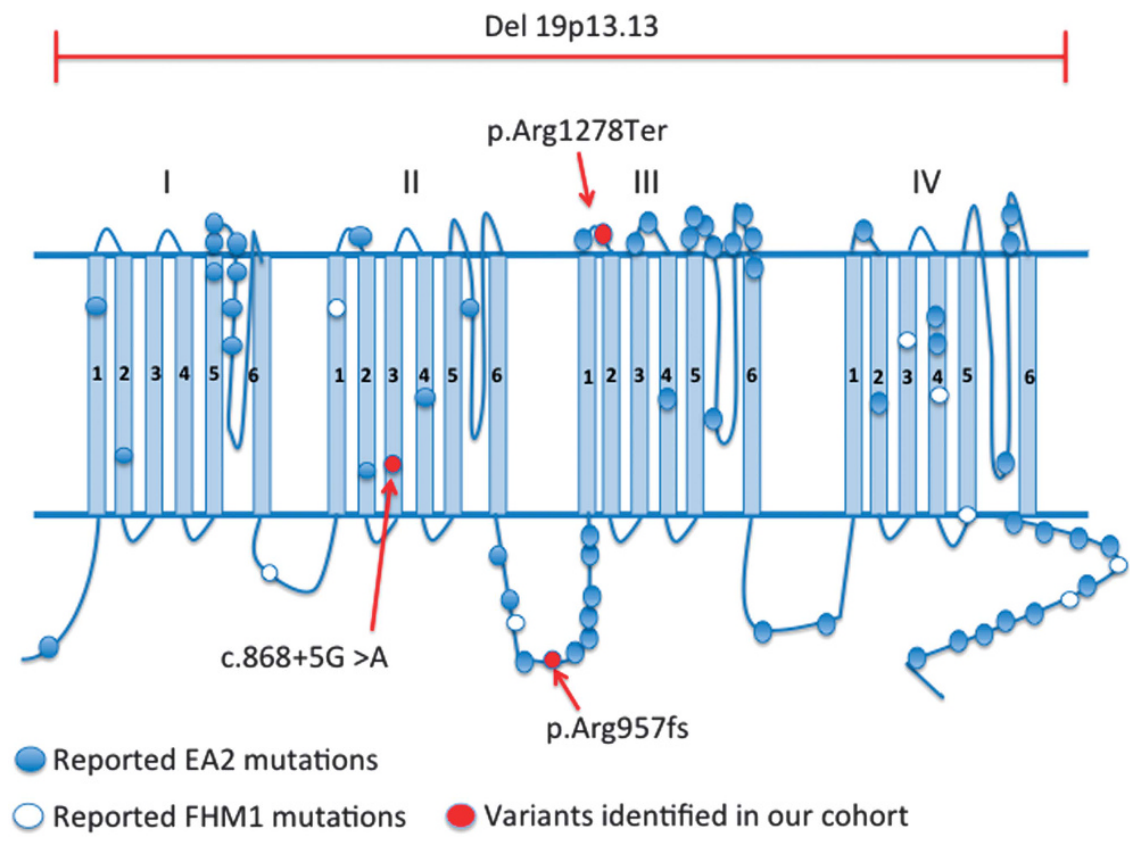

Figure $2 \mathrm{New}$ and previously reported mutations in Cav2.1. Previously reported mutations in CACNA1A, causing either episodic ataxia type II (EA2; blue circles) or familial hemiplegic migraine type I (FHM1; white circles) affect most domains of the alpha1 subunit of the Cav2.1 calcium channel, as illustrated here (adapted from Mantuano et al, 2010). Red circles illustrate loss-of-function mutations reported in this publication.

1-2 $\mathrm{h}$ and occurring multiple times a week since the age of 12 , for which she had never consulted. Her episodes resolved with acetazolamide. Her examination reveals downbeat nystagmus, without dysmetria or ataxia. Her maternal grandmother (patient 1.1) had presented similar episodes of ataxia with nystagmus for which she never sought medical attention. She had lost a son (patient 2.1) at 18 months of age of severe refractory epilepsy.

The child's maternal uncle (patient 3.2) presents episodes of intermittent ataxia, nystagmus and oscillopsia, lasting 10-15 min, occurring multiple times per week, precipitated by stress, emotion and exertion, since the age of 11 . These events respond partially to acetazolamide. He also presented episodes of stress-induced cataplexy, without myokymia or myotonia. He had mild ID and required special schooling. He is currently unemployed. He developed a progressive ataxia with dysarthria in his forties. His neurological examination reveals dysmetria, gait ataxia and diffuse hyporeflexia.

This man has a 13-year-old daughter (patient 4.2), born at term from an uneventful pregnancy. At 6 months of age, she developed episodes of vertigo and ataxia with vomiting. She learned to walk at 16 months of age and was ataxic from the onset. She remained with paroxysmal episodes of ataxia, nytagmus and malaise lasting $1 \mathrm{~h}$, recurring daily, precipitated by exertion or fatigue, sometimes 
accompanied by headaches. These episodes are partially responsive to acetazolamide. Between episodes, she had progressive gait ataxia and downbeat nystagmus with vertical oscillopsia. She presented recurrent generalized febrile seizures from 15 months to 9 years of age. In addition, she had cognitive deficits with learning disabilities, ADHD and behavioral difficulties and required special schooling. Her global IQ was evaluated at 71 on WISC-IV testing. Her neurological examination is remarkable for downbeat nystagmus, truncal ataxia, ataxic gait and diffuse hyporeflexia.

The metabolic workup and CGH assay for both children as well as brain MRIs were unremarkable. CACNA1A sequencing revealed a new frameshift variant in exon 19, c.2867_2869del (p.(Arg957fs; NM_001174080.1; NG_011569.1)).

\section{Family 3}

Patient 3.1, now 16 years old, was born prematurely at 34 weeks of gestation from an unremarkable delivery. He presented with DD and unsteady gait since he learned to walk at 2 years of age. Around 4 years of age, he developed daily episodes of oscillopsia and ataxia leading to falls, lasting 15-30 min, triggered by exertion or stress. His episodes responded completely to acetazolamide. He remained with intercurrent nystagmus and unsteady gait. He had one brief generalized tonicclonic febrile seizure before age 4 . He had mild ID (global IQ: 72), $\mathrm{ADHD}$, dyslexia and required special schooling. His neurological examination revealed downbeat nystagmus, horizontal gaze-evoked nystagmus, saccadic visual pursuit, hypermetric saccades, limb hypotonia, unsteady gait during rapid direction changes and no dysmetria.

The boy's mother (patient 2.1) aged 50 years presented during childhood with learning difficulties requiring special schooling, ADHD and dropped out of school after grade 9 . She is currently unemployed. Since 6 years of age, she presented daily episodes of unsteady gait, nystagmus, malaise lasting $2-3 \mathrm{~h}$, precipitated by stress, fatigue or exertion. These had been wrongly attributed to anxiety for which she received benzodiazepines, but responded completely to acetazolamide. She developed a progressive gait ataxia, mild dysarthria and persistent nystagmus, which became symptomatic at the age of 42 years. Her neurological examination revealed downbeat nystagmus and horizontal gaze-evoked nystagmus, hypermetric saccades, mild dysarthria, a gait ataxia and hand clumsiness without dysmetria.

The boy's investigation included a normal karyotype, fragile $\mathrm{X}$ screen and metabolic workup. His brain MRI revealed a non-specific millimetric T2 signal hyperintensity in the left globus pallidus. CACNA1A sequencing in both individuals revealed a new splice-site variant, c.868+5G > A (NG_011569.1; NM_000068.3), predicted to be pathogenic by abolishing a known splice site for exon 4. Deletion of this conserved exon leads to a clear loss-of-function in mice models of the disease. ${ }^{15,16}$

\section{Family 4}

Patient 3.1 was born at 36 weeks after an uneventful pregnancy. At 8 months of age, he presented with recurrent afebrile episodes of altered consciousness with eyeball revulsion lasting 10-20 s. He also presented three brief generalized tonic-clonic seizures. His EEG and brain MRI were unremarkable. He was treated with carbamazepine, which was replaced by lamotrigine when seizures recurred. At 12 months of age, the patient developed recurring episodes of ataxia and nystagmus, lasting 12-24 h, during which he laid on the ground and refused to stand. Acetazolamide treatment reduced the duration of these episodes, although they persist at a frequency of two to three times per month at 2.5 years of age. The episodes are often accompanied by headache and vomiting, and sometimes require hospitalization for analgesia and rehydration. The boy displayed a global DD, walked independently at 24 months and is clumsy on fine motor skills. He spoke his first intelligible words at 26 months. At 2.5 years of age, his vocabulary was restricted to six words and he could not juxtapose words. He was socially awkward, does not point, drags the adults toward objects of interest, has stereotypic and restricted interests, was impulsive and inattentive and his ADOS confirmed ASD. His examination at 2.5 years of age revealed emotional lability, poor eye contact, bilateral epicanthal folds, mild limb hypotonia, truncal ataxia, unsteady gait with wide base and no dysmetria.

His sister (patient 3.2) was born at term after an uneventful pregnancy. She presented with global DD: she walked at 15 months, had poor fine motor skills, spoke her first words at 15 months but sentences only at 4 years of age. She had mild-moderate ID (global IQ: 58 on WISC-IV testing), ADHD and anxiety, and she required special schooling. She developed episodic ataxia at 15 months of age, with episodes lasting $1 \mathrm{~h}$, every 2 weeks, triggered by fever, infections or vestibular stimulation (swing). These events improved with acetazolamide. She also reported tension headaches once a month. Her examination at 11.5 years of age revealed downbeat nystagmus, mild dysarthria, discrete dysmetria, clumsiness on rapidly alternating movements and inability to perform repetitive motor sequences (perseveration and impulsivity), but no ataxia. Her brain MRI and EEG were unremarkable. A complete metabolic workup at 15 months of age was negative.

The mother (patient 2.1), now aged 33, had a normal early development but presented significant learning disabilities with $\mathrm{ADHD}$, required special schooling from the first grade onwards and dropped out of school after 10 years. She is currently unemployed. Her cognitive abilities were not formally tested but she was reported to have mild ID. She developed episodic ataxia at 21 years of age, with episodes lasting $2-3 \mathrm{~h}$, recurring once a month, triggered by stress and exercise. She also developed progressive interictal gait instability since the age of 32 years and falls frequently. She reported migraines on a monthly basis. Her brain MRI was unremarkable. Her physical examination revealed executive slowing, a downbeat nystagmus, mild dysarthria, bilateral clumsiness on rapidly alternating movements, no frank dysmetria, no frank ataxia but gait instability on rapid direction changes and unstable tandem walking.

CGH in both children revealed a maternally inherited $0.085 \mathrm{Mb}$ deletion on chromosome 19: Chr19.hg18:g.13,380,344_13,465,506del (hg18/NCBI36; NG_011569.1; Del19p13.13), within the CACNA1A gene and spanning most of the gene.

\section{DISCUSSION}

We reported 16 affected individuals from four non-consanguineous families carrying CACNA1A loss-of-function variants. Although all of our patients displayed mild intermittent cerebellar symptoms, their most striking features were the cognitive or behavioral impairments and seizure susceptibility that accompanied their disorder. This report therefore stresses the significant non-cerebellar symptoms associated with CACNA1A haploinsufficiency.

The initial presentation in our patients were diverse and included epileptic encephalopathy with generalized epilepsy, DD with febrile seizures, DD with autism spectrum disorder (ASD) or learning disabilities with episodic ataxia. The acute cerebellar symptoms displayed by our patients were either an isolated downbeat nystagmus $(n=2 / 16,13 \%)$ or episodes of intermittent ataxia, oscillopsia and nystagmus typical of EA2. These episodes vary in intensity from a few seconds to hours, are typically provoked by stress, exertion, fatigue or illness and vary in frequency between individuals, from weekly 
episodes to rare annual episodes. Most patients $(n=12 / 16,75 \%)$ developed progressive ataxia during adolescence or adulthood and the majority present interictal downbeat nystagmus $(n=14 / 16,88 \%)$. This is consistent with the current literature describing progressive ataxia in $80 \%$ of patients with $\mathrm{EA} 2^{7}$ and persistent nystagmus in $90 \%$ of patients. ${ }^{10}$ Nonetheless, in six individuals, the ataxia did not dominate the initial presentation and was only revealed by close questioning of relatives for whom the cerebellar symptoms had been misdiagnosed as anxiety or hormonal imbalance.

A significant proportion of our patients presented with DD $(n=6 / 16,38 \%)$, ID $(n=6 / 16,38 \%)$ or learning difficulties $(n=4 / 16$, $25 \%)$, often with ADHD and impulsivity $(n=11 / 16,69 \%)$. These deficits were apparent from early childhood and had significant impact on the patient's educational path and social integration. In addition, three children carry a diagnosis of ASD and another has altered social skills with stereotypic behaviors suggestive of ASD $(n=4 / 16,25 \%)$. Cognitive and behavioral impairments have been reported in a minority of patients with CACNA1A mutations, including in two children with sporadic epileptic encephalopathies, ${ }^{17,18}$ in six children with EA2 and ID, ${ }^{19-22}$ including two siblings with a $19 \mathrm{p} 13.13$ deletion. ${ }^{23}$ Rare cases of FHM1 with ID $^{24}$ and progressive cognitive decline $^{24-26}$ have been reported. Therefore, our data together with previous reports suggest that children with global DD, ID or ASD with mild cerebellar symptoms, with or without a family history suggestive of EA2, should be investigated for loss-of-function mutations in the CACNA1A gene.

In addition, the patients described here presented a high rate of epilepsy or febrile seizures. Indeed, three children from three unrelated families presented with epileptic encephalopathy with either generalized absence seizures or focal seizures with or without generalized tonic-clonic seizures $(n=3 / 16,19 \%)$. In addition, six patients $(n=6 / 15$, $40 \%$ ) had febrile seizures during childhood. CACNA1A loss-offunction mutations have been associated with rare cases of generalized absence epilepsy $y^{22,27-32}$ or epileptic encephalopathy. ${ }^{17,18}$ Furthermore, up to $7 \%$ of patients with EA2 were described to develop absence epilepsy, as reviewed by Rajakulendran et al. ${ }^{11}$ The current report illustrates the higher rate of febrile seizures or epilepsy in patients with loss-of-function mutations in CACNA1A, which might represent only a fraction of EA2 cases. Perhaps most importantly, our report indicates that mutations in CACNA1A should be excluded in children with developmental disorders and refractory generalized epilepsy even in the absence of frank cerebellar symptoms. A downbeat nystagmus was observed in most of our patients and might alert clinicians to this genetic condition in children with refractory epilepsy. ${ }^{33-39}$

Mechanistically, $\mathrm{Ca}_{\mathrm{V}} 2.1$ channels are voltage-gated calcium channels expressed at the pre-synaptic and somatodendritic level of a variety of cerebral and spinal neuronal populations. ${ }^{15,40,41} \mathrm{Ca}_{\mathrm{v}} 2.1$ channels have been shown to mediate synaptic release from a variety of neuronal cell types, both excitatory and inhibitory, in the cortex, hippocampus, thalamus and cerebellum. ${ }^{15,42-49}$ The loss of $\mathrm{Ca}_{\mathrm{V}} 2.1$ channels is compensated by upregulation of other voltage-gated calcium channels at most central synapses, ${ }^{15,44,47-49}$ although with different efficiency, ${ }^{50}$ resulting in synaptic dysfunction of particular cell types leading to pathological manifestations. In cerebellar networks, $\mathrm{Ca}_{V} 2.1$ channels regulate the whole-cell calcium current density and the intrinsic excitability of Purkinje cells and granule cells, ${ }^{44,51-53}$ and exert major control over glutamate release at the parallel fiber onto Purkinje-cell synapses. ${ }^{50,54-56}$ Furthermore, targeted deletions of Cacnala in cerebellar granule cells ${ }^{57}$ or in Purkinje cells ${ }^{58}$ result in altered cerebellar output by respectively decreasing the excitatory drive on Purkinje cells or their ability to release neurotransmitters, causing ataxia and dyskinesia in mice.

Within the thalamus, constitutive dysfunction of $\mathrm{Ca}_{\mathrm{V}} 2.1$ channels in the Cacnal $a^{\text {tg/tg }}$ mutant mice result in a gain of function of Cav3.1 T-type calcium channels in the reticular nucleus and in a persistent tonic thalamic $\mathrm{GABA}_{\mathrm{A}}$ current in thalamocortical projection neurons, which together enhance thalamocortical excitation and contribute to the spike-wave absence seizures phenotype. ${ }^{59-63}$ In the neocortex and hippocampus, $\mathrm{Ca}_{\mathrm{V}} 2.1$ channels have been demonstrated to mediate GABA release and synaptic efficiency from cortical GABAergic parvalbumin-positive fast-spiking interneurons (FS-INs) ${ }^{15,42,43,47}$ as well as from cortical pyramidal cells. ${ }^{15}$ We recently demonstrated that a selective deletion of Cacnala from cortical and hippocampal GABAergic interneurons, while sparing the thalamus and cerebellum, selectively impairs GABA release from FS-INs, despite an upregulation of N-type channels, and that this is sufficient to cause generalized epilepsy in conditional mutant mice. ${ }^{15}$ Of note, the selective deletion of Cacna1a in cortical pyramidal cells did not cause seizures but its combination with forebrain GABAergic interneuron Cacnala deletion reduced seizure severity. These studies revealed the importance of $\mathrm{Ca}_{\mathrm{V}} 2.1$ channels in regulating synaptic release from cortical FS-INs and the potential involvement of these cell types in Cacnala-associated epilepsy.

The mechanisms underlying cognitive dysfunction in Cacnala mutants are uncertain. Progressive cognitive deficits have been reported in the heterozygous leaner mutant mice Cacnalatg(la)/+ 64,65 and in the heterozygous Nogoya mutant mice. ${ }^{66}$ The cerebellum projects directly and indirectly to many cortical and limbic structures involved in learning and cognition, ${ }^{67-69}$ and deregulation of these projections might impair cortical and limbic processes, including motor memory consolidation. ${ }^{70}$ In addition, cortical inhibitory defects have been postulated to result in a variety of neurobehavioral phenotypes in humans and rodents, including cognitive dysfunction, social deficits and autism,,$^{71-76}$ and could contribute to cognitive impairment following Cacnala mutations. Indeed, cortical and limbic GABAergic interneurons regulate the synchrony of neuronal firing in populations of neurons and participate in the generation of highfrequency gamma oscillations involved in cognitive processes and attention. ${ }^{77-86}$

In summary, the current report illustrates the spectrum of neurobehavioral symptoms associated with CACNA1A loss-offunction mutations in humans. Such behavioral phenotypes might be overlooked in patients when the epilepsy or ataxia are predominant, but a careful consideration of potential cognitive and behavioral consequences in these patients might allow for an earlier instauration of cognitive-behavioral interventions and improve long-term outcome. Furthermore, we propose that targeted sequencing of the CACNA1A gene should be considered in children presenting with downbeat nystagmus together with epileptic encephalopathy, cognitive impairment or ASD.

\section{CONFLICT OF INTEREST}

The authors declare no conflict of interest.

\section{ACKNOWLEDGEMENTS}

We are grateful to the patients and families who accepted to participate in this study. This work was supported by grants from the FRQS (E. Rossignol

Clinician-Scientist Junior I) and the Savoy Foundation. 
1 Ophoff RA, Terwindt GM, Vergouwe MN et al: Familial hemiplegic migraine and episodic ataxia type- 2 are caused by mutations in the Ca2+ channel gene CACNL1A4. Cell 1996; 87: 543-552.

2 Ducros A, Denier C, Joutel A et al: Recurrence of the T666M calcium channel CACNA1A gene mutation in familial hemiplegic migraine with progressive cerebellar ataxia. Am J Hum Genet 1999; 64: 89-98.

3 Zhuchenko O, Bailey J, Bonnen P et al: Autosomal dominant cerebellar ataxia (SCA6) associated with small polyglutamine expansions in the alpha $1 \mathrm{~A}$-voltage-dependent calcium channel. Nat Genet 1997; 15: 62-69.

4 Alonso I, Barros J, Tuna A et al: Phenotypes of spinocerebellar ataxia type 6 and familial hemiplegic migraine caused by a unique CACNA1A missense mutation in patients from a large family. Arch Neurol 2003; 60: 610-614.

5 Mantuano E, Romano S, Veneziano $L$ et al: Identification of novel and recurrent CACNA1A gene mutations in fifteen patients with episodic ataxia type 2. J Neurol Sci 2010; 291: 30-36.

6 Geschwind DH, Perlman S, Figueroa KP et al: Spinocerebellar ataxia type 6. Frequency of the mutation and genotype-phenotype correlations. Neurology 1997; 49: 1247-1251.

7 Baloh RW, Yue Q, Furman JM et al: Familial episodic ataxia: clinical heterogeneity in four families linked to chromosome 19p. Ann Neurol 1997; 41: 8-16.

8 von Brederlow B, Hahn AF, Koopman WJ et al: Mapping the gene for acetazolamide responsive hereditary paryoxysmal cerebellar ataxia to chromosome 19p. Hum $\mathrm{Mol}$ Genet 1995; 4: 279-284.

9 Spacey S: Episodic ataxia type 2; In Pagon RA, Adam MP, Bird TD et al: (eds) Seattle (WA): GeneReviews, 1993.

10 Jen J, Kim GW, Baloh RW: Clinical spectrum of episodic ataxia type 2. Neurology 2004; 62: 17-22.

11 Rajakulendran S, Graves TD, Labrum RW et al: Genetic and functional characterisation of the $P / Q$ calcium channel in episodic ataxia with epilepsy. J Physiol 2010; 588: 1905-1913.

12 Yue Q, Jen JC, Thwe MM et al: De novo mutation in CACNA1A caused acetazolamideresponsive episodic ataxia. Am J Med Genet 1998; 77: 298-301.

13 Steckley JL, Ebers GC, Cader MZ et al: An autosomal dominant disorder with episodic ataxia, vertigo, and tinnitus. Neurology 2001; 57: 1499-1502.

14 Michaud JL, Lachance M, Hamdan FF et al: The genetic landscape of infantile spasms. Hum Mol Genet 2014; 23: 4846-4858.

15 Rossignol E, Kruglikov I, van den Maagdenberg AM et al: CaV 2.1 ablation in cortical interneurons selectively impairs fast-spiking basket cells and causes generalized seizures. Ann Neurol 2013; 74: 209-222.

16 Todorov B, van de Ven RC, Kaja S et al: Conditional inactivation of the Cacnala gene in transgenic mice. Genesis 2006; 44: 589-594.

17 Allen AS, Berkovic SF, Cossette $P$ et al: De novo mutations in epileptic encephalopathies. Nature 2013; 501: 217-221.

18 Auvin S, Holder-Espinasse M, Lamblin MD et al: Array-CGH detection of a de novo 0.7- Mb deletion in 19p13.13 including CACNA1A associated with mental retardation and epilepsy with infantile spasms. Epilepsia 2009; 50: 2501-2503.

19 Bertholon P, Chabrier S, Riant F et al: Episodic ataxia type 2: unusual aspects in clinical and genetic presentation. Special emphasis in childhood. J Neurol Neurosurg Psychiatry 2009; 80: 1289-1292.

20 Blumkin L, Michelson M, Leshinsky-Silver E et al: Congenital ataxia, mental retardation, and dyskinesia associated with a novel CACNA1A mutation. J Child Neurol 2010; 25: 892-897.

21 Guerin AA, Feigenbaum A, Donner EJ et al: Stepwise developmental regression associated with novel CACNA1A mutation. Pediatr Neurol 2008; 39: 363-364.

22 Jung J, Testard $\mathrm{H}$, Tournier-Lasserve $\mathrm{E}$ et al: Phenotypic variability of episodic ataxia type 2 mutations: a family study. Eur Neurol 2010; 64: 114-116.

23 Nimmakayalu M, Horton VK, Darbro B et al: Apparent germline mosaicism for a novel 19 p13.13 deletion disrupting NFIX and CACNA1A. Am J Med Genet A 2013; 161 A: 1105-1109.

24 Freilinger $\mathrm{T}$, Bohe $\mathrm{M}$, Wegener $\mathrm{B}$ et al: Expansion of the phenotypic spectrum of the CACNA1A T666M mutation: a family with familial hemiplegic migraine type 1, cerebellar atrophy and mental retardation. Cephalalgia 2008; 28: 403-407.

25 Kors EE, Haan J, Giffin NJ et al: Expanding the phenotypic spectrum of the CACNA1A gene T666M mutation: a description of 5 families with familial hemiplegic migraine. Arch Neurol 2003; 60: 684-688.

26 Karner E, Nachbauer W, Bodner T et al: Long-term outcome of cognitive functions, emotional behavior, and quality of life in a family with familial hemiplegic migraine. Cogn Behav Neurol 2012; 25: 85-92.

27 Chioza B, Wilkie $H$, Nashef $L$ et al: Association between the alpha(1a) calcium channel gene CACNA1A and idiopathic generalized epilepsy. Neurology 2001; 56: $1245-1246$

28 Jouvenceau A, Eunson LH, Spauschus A et al: Human epilepsy associated with dysfunction of the brain P/Q-type calcium channel. Lancet 2001; 358: 801-807.

29 Imbrici P, Jaffe SL, Eunson LH et al: Dysfunction of the brain calcium channel CaV2.1 in absence epilepsy and episodic ataxia. Brain 2004; 127: 2682-2692.

30 Escayg A, De Waard M, Lee DD et al: Coding and noncoding variation of the human calcium-channel beta4-subunit gene CACNB4 in patients with idiopathic generalized epilepsy and episodic ataxia. Am J Hum Genet 2000; 66: 1531-1539.

31 Khosravani H, Altier C, Simms B et al: Gating effects of mutations in the Cav3.2 T-type calcium channel associated with childhood absence epilepsy. J Biol Chem 2004; 279: 9681-9684.
32 Chen Y, Lu J, Pan $\mathrm{H}$ et al: Association between genetic variation of CACNA1H and childhood absence epilepsy. Ann Neurol 2003; 54: 239-243.

33 Riant $\mathrm{F}$, Lescoat $\mathrm{C}$, Vahedi $\mathrm{K}$ et al: Identification of CACNA1 A large deletions in four patients with episodic ataxia. Neurogenetics 2010; 11: 101-106.

34 Cuenca-Leon E, Banchs I, Serra SA et al: Late-onset episodic ataxia type 2 associated with a novel loss-of-function mutation in the CACNA1 A gene. J Neurol Sci 2009; 280 . 10-14.

35 Eunson LH, Graves TD, Hanna MG: New calcium channel mutations predict aberrant RNA splicing in episodic ataxia. Neurology 2005; 65: 308-310.

36 Labrum RW, Rajakulendran S, Graves TD et al: Large scale calcium channel gene rearrangements in episodic ataxia and hemiplegic migraine: implications for diagnostic testing. J Med Genet 2009; 46: 786-791.

37 Kaunisto MA, Harno H, Kallela M et al: Novel splice site CACNA1A mutation causing episodic ataxia type 2. Neurogenetics 2004; 5: 69-73.

38 Zasorin NL, Baloh RW, Myers LB: Acetazolamide-responsive episodic ataxia syndrome. Neurology 1983; 33: 1212-1214.

39 Wan J, Carr JR, Baloh RW et al: Nonconsensus intronic mutations cause episodic ataxia. Ann Neurol 2005; 57: 131-135.

40 Ludwig A, Flockerzi V, Hofmann F: Regional expression and cellular localization of the alpha1 and beta subunit of high voltage-activated calcium channels in rat brain. J Neurosci 1997; 17: 1339-1349.

41 Westenbroek RE, Sakurai T, Elliott EM et al: Immunochemical identification and subcellular distribution of the alpha $1 \mathrm{~A}$ subunits of brain calcium channels. J Neurosci 1995; 15: 6403-6418.

42 Zaitsev AV, Povysheva NV, Lewis DA et al: P/Q-type, but not N-type, calcium channels mediate GABA release from fast-spiking interneurons to pyramidal cells in rat prefrontal cortex. J Neurophysiol 2007; 97: 3567-3573.

43 Sasaki S, Huda K, Inoue T et al: Impaired feedforward inhibition of the thalamocortical projection in epileptic Ca2+ channel mutant mice, tottering. J Neurosci 2006; 26: 3056-3065.

44 Jun K, Piedras-Renteria ES, Smith SM et al: Ablation of $\mathrm{P} / \mathrm{Q}$-type $\mathrm{Ca}(2+)$ channel currents, altered synaptic transmission, and progressive ataxia in mice lacking the alpha(1A)-subunit. Proc Natl Acad Sci USA 1999; 96: 15245-15250.

45 Caddick SJ, Wang C, Fletcher CF et al: Excitatory but not inhibitory synaptic transmission is reduced in lethargic (Cacnb4(Ih)) and tottering (Cacnalatg) mouse thalami. J Neurophysiol 1999; 81: 2066-2074.

46 Ali AB, Nelson C: Distinct $\mathrm{Ca} 2+$ channels mediate transmitter release at excitatory synapses displaying different dynamic properties in rat neocortex. Cereb Cortex 2006; 16: 386-393.

47 Kruglikov I, Rudy B: Perisomatic GABA release and thalamocortical integration onto neocortical excitatory cells are regulated by neuromodulators. Neuron 2008; 58 : 911-924.

48 Qian J, Noebels JL: Presynaptic $\mathrm{Ca}(2+)$ influx at a mouse central synapse with $\mathrm{Ca}(2+)$ channel subunit mutations. J Neurosci 2000; 20: 163-170.

49 Cao $Y Q$, Tsien RW: Effects of familial hemiplegic migraine type 1 mutations on neuronal $\mathrm{P} / \mathrm{Q}$-type $\mathrm{Ca} 2+$ channel activity and inhibitory synaptic transmission. Proc Nat/ Acad Sci USA 2005; 102: 2590-2595.

50 Matsushita K, Wakamori M, Rhyu IJ et al: Bidirectional alterations in cerebellar synaptic transmission of tottering and rolling $\mathrm{Ca} 2+$ channel mutant mice. J Neurosci 2002; 22: 4388-4398.

51 Lau FC, Abbott LC, Rhyu IJ et al: Expression of calcium channel alpha1A mRNA and protein in the leaner mouse (tgla/tgla) cerebellum. Brain Res Mol Brain Res 1998; 59: 93-99.

52 Llinas R, Sugimori M: Electrophysiological properties of in vitro Purkinje cell dendrites in mammalian cerebellar slices. J Physiol 1980; 305: 197-213.

53 Llinas R, Sugimori M: Electrophysiological properties of in vitro Purkinje cell somata in mammalian cerebellar slices. J Physiol 1980; 305: 171-195.

54 Mintz IM, Sabatini BL, Regehr WG: Calcium control of transmitter release at a cerebellar synapse. Neuron 1995; 15: 675-688.

55 Myoga MH, Regehr WG: Calcium microdomains near R-type calcium channels control the induction of presynaptic long-term potentiation at parallel fiber to purkinje cell synapses. J Neurosci 2011; 31: 5235-5243.

56 Liu S, Friel DD: Impact of the leaner P/Q-type Ca2+ channel mutation on excitatory synaptic transmission in cerebellar Purkinje cells. J Physiol 2008; 586: 4501-4515.

57 Maejima T, Wollenweber P. Teusner LU et al: Postnatal loss of P/Q-type channels confined to rhombic-lip-derived neurons alters synaptic transmission at the parallel fiber to purkinje cell synapse and replicates genomic Cacnala mutation phenotype of ataxia and seizures in mice. J Neurosci 2013; 33: 5162-5174.

58 Mark MD, Maejima T, Kuckelsberg D et al: Delayed postnatal loss of P/Q-type calcium channels recapitulates the absence epilepsy, dyskinesia, and ataxia phenotypes of genomic Cacnala mutations. J Neurosci 2011; 31: 4311-4326.

59 Llinas RR, Choi S, Urbano FJ et al: Gamma-band deficiency and abnormal thalamocortical activity in P/Q-type channel mutant mice. Proc Natl Acad Sci USA 2007; 104: 17819-17824.

60 Talley EM, Solorzano G, Depaulis A et al: Low-voltage-activated calcium channel subunit expression in a genetic model of absence epilepsy in the rat. Brain Res $\mathrm{Mol}$ Brain Res 2000; 75: 159-165.

61 Tsakiridou $E$, Bertollini $L$, de Curtis $M$ et al: Selective increase in T-type calcium conductance of reticular thalamic neurons in a rat model of absence epilepsy. J Neurosci 1995; 15: 3110-3117.

62 Zhang Y, Mori M, Burgess DL et al: Mutations in high-voltage-activated calcium channel genes stimulate low-voltage-activated currents in mouse thalamic relay neurons. J Neurosci 2002; 22: 6362-6371. 
63 Cope DW, Di Giovanni G, Fyson SJ et al: Enhanced tonic GABAA inhibition in typical absence epilepsy. Nat Med 2009; 15: 1392-1398.

64 Marques JM, Alonso I, Santos C et al: The spatial learning phenotype of heterozygous leaner mice is robust to systematic variation of the housing environment. Comp Med 2009; 59: 129-138.

65 Alonso I, Marques JM, Sousa N et al: Motor and cognitive deficits in the heterozygous leaner mouse, a Cav2.1 voltage-gated Ca2+ channel mutant. Neurobiol Aging 2008; 29: 1733-1743.

66 Takahashi E, Niimi K: Spatial learning deficit in aged heterozygous Cav2.1 channel mutant mice, rolling mouse Nagoya. Exp Gerontol 2009; 44: 274-279.

67 Krienen FM, Buckner RL: Segregated fronto-cerebellar circuits revealed by intrinsic functional connectivity. Cereb Cortex 2009; 19: 2485-2497.

68 Kelly RM, Strick PL: Cerebellar loops with motor cortex and prefrontal cortex of a nonhuman primate. J Neurosci 2003; 23: 8432-8444.

69 Schmahmann JD, Pandya DN: Anatomical investigation of projections to the basis pontis from posterior parietal association cortices in rhesus monkey. J Comp Neurol 1989; 289: 53-73.

70 Galliano E, Gao Z, Schonewille M et al: Silencing the majority of cerebellar granule cells uncovers their essential role in motor learning and consolidation. Cell Rep 2013; 3: $1239-1251$.

71 Liu X, Novosedlik N, Wang A et al: The DLX1and DLX2 genes and susceptibility to autism spectrum disorders. Eur J Hum Genet 2009; 17: 228-235.

72 Powell EM, Campbell DB, Stanwood GD et al: Genetic disruption of cortical interneuron development causes region- and GABA cell type-specific deficits, epilepsy, and behavioral dysfunction. J Neurosci 2003; 23: 622-631.

73 Levitt P, Eagleson KL, Powell EM: Regulation of neocortical interneuron development and the implications for neurodevelopmental disorders. Trends Neurosci 2004; 27: 400-406.

74 Rossignol E: Genetics and function of neocortical GABAergic interneurons in neurodevelopmental disorders. Neural Plast 2011; 2011: 649325.
75 Lewis DA, Hashimoto T, Volk DW: Cortical inhibitory neurons and schizophrenia. Nat Rev Neurosci 2005; 6: 312-324.

76 Akbarian S, Huang HS: Molecular and cellular mechanisms of altered GAD1/GAD67 expression in schizophrenia and related disorders. Brain Res Rev 2006; 52: 293-304.

77 Cardin JA, Carlen M, Meletis $\mathrm{K}$ et al: Driving fast-spiking cells induces gamma rhythm and controls sensory responses. Nature 2009; 459: 663-667.

78 Bartos M, Vida I, Frotscher M et al: Fast synaptic inhibition promotes synchronized gamma oscillations in hippocampal interneuron networks. Proc Natl Acad Sci USA 2002; 99: 13222-13227.

79 Bartos M, Vida I, Jonas P: Synaptic mechanisms of synchronized gamma oscillations in inhibitory interneuron networks. Nat Rev Neurosci 2007; 8: 45-56.

80 Buhl DL, Harris KD, Hormuzdi SG et al: Selective impairment of hippocampal gamma oscillations in connexin-36 knock-out mouse in vivo. J Neurosci 2003; 23. 1013-1018.

81 Colgin LL, Moser El: Gamma oscillations in the hippocampus. Physiology (Bethesda) 2010; 25: 319-329.

82 Fisahn A, Neddens J, Yan L et al: Neuregulin-1 modulates hippocampal gamma oscillations: implications for schizophrenia. Cereb Cortex 2009; 19: 612-618.

83 Howard MW, Rizzuto DS, Caplan JB et al: Gamma oscillations correlate with working memory load in humans. Cereb Cortex 2003; 13: 1369-1374.

84 Sohal VS, Zhang F, Yizhar 0 et al: Parvalbumin neurons and gamma rhythms enhance cortical circuit performance. Nature 2009; 459: 698-702.

85 Tallon-Baudry C, Bertrand O, Peronnet F et al: Induced gamma-band activity during the delay of a visual short-term memory task in humans. J Neurosci 1998; 18: 4244-4254.

86 Traub RD, Cunningham MO, Gloveli T et al: GABA-enhanced collective behavior in neuronal axons underlies persistent gamma-frequency oscillations. Proc Natl Acad SC USA 2003; 100: 11047-11052.

Supplementary Information accompanies this paper on European Journal of Human Genetics website (http://www.nature.com/ejhg) 